\title{
Influência da assistência de enfermagem na prática da amamentação no puerpério imediato*
}

Influence of nursing care in the practice of the breastfeeding in the immediate postpartum

Kadydja Russell de Araújo Batista', Maria do Carmo Andrade Duarte de Farias², Wanderson dos

Santos Nunes de Melo ${ }^{3}$

' Especialista em Enfermagem do Trabalho pelas Faculdades Integradas de Patos (FIP) Patos (PB), Brasil.

kadydjarapc@hotmail.com

${ }^{2}$ Pós-doutoranda pela Faculdade de Medicina do ABC - Santo André (SP), Brasil. Professora associado II da Universidade Federal de Campina Grande (UFCG) Cajazeiras (PB), Brasil.

carmofarias@hotmail.com

${ }^{3}$ Especialista em Enfermagem do Trabalho pelas Faculdades Integradas de Patos (FIP) Patos (PB), Brasil.

wanderson180487@hotmail.com
RESUMO Com o objetivo de compreender a prática do enfermeiro, como suporte social, em relação ao aleitamento materno, esta pesquisa qualitativa investigou 16 mulheres que viveram a amamentação. Com roteiro estruturado, os dados foram coletados, analisados através da temática tradicional e discutidos à luz da literatura. Os resultados revelam que, para a maioria das entrevistadas, a contribuição da enfermeira não foi satisfatória, pois esteve ausente no enfrentamento das dificuldades, resultando no desmame precoce. Almejamos que haja assistência de enfermagem no puerpério imediato com ações comunitárias de promoção à saúde, a fim atingir o recomendado pelo Ministério da Saúde, acerca da amamentação.

PALAVRAS CHAVE: Aleitamento materno; assistência de enfermagem; desmame.

\begin{abstract}
In order to understand the practice of the nurse, as social support in relation to breastfeeding, this qualitative research investigated 16 women who experienced breastfeeding. With a structured script the data were collected, analyzed by the traditional theme and discussed in light of the literature. The results reveal that, for most women surveyed, the contribution of the nurse was not satisfactory because she was absent facing the difficulties, resulting in premature weaning. We desire that the nursing care in the postpartum, be reality, and community actions to promote health in order to achieve the recommended by the Ministry of Health regarding breastfeeding be developed.
\end{abstract}

KEYWORDS: Breast feeding; nursing care; weaning.

"Parte da monografia - Prática da amamentação analisada sob a influência da assistência de enfermagem no puerpério imediato, apresentada à Coordenação em Enfermagem da Universidade Federal de Campina Grande (UFCG) em 02 dez. 2011. 


\section{Introdução}

A prática do aleitamento materno está relacionada a fatores de ordem física, psicológica e social, sendo reconhecida a influência dos profissionais de saúde envolvidos neste processo (MARINHO; LEAL, 2004).

A partir de 1981, o Brasil passou por importantes transformaçôes sociais no cenário do aleitamento materno, com o desenvolvimento de uma política estatal, estabelecida pelo Ministério da Saúde, focada na temática específica para o setor saúde (SYDRONIO, 2006). Entretanto, não obstante o incentivo à amamentação e a sua comprovada importância, o desmame precoce é uma realidade ainda predominante.

Supóe-se que uma das justificativas para essa realidade seja o fato de os profissionais de saúde terem atitudes e discursos favoráveis ao ato de amamentar, mas muitas vezes não estão próximos, vivenciando os momentos de (in)sucesso da mulher no processo de lactação. $\mathrm{O}$ enfermeiro é o profissional que deve ser capaz de identificar e oportunizar momentos educativos, facilitando a amamentação, o diagnóstico e o tratamento adequados, considerando ser ele capacitado em aleitamento materno, e que poderá atuar junto à população, não somente prestando assistência, mas também na promoção e educação continuada, de forma efetiva (AMORIM; ANDRADE, 2009). Desta forma, ter como estratégia a promoção da saúde, reconhecendo que, entre outros princípios, educação e alimentação são fundamentais; e que deve propiciar, sobretudo, o fortalecimento das ações comunitárias e o desenvolvimento de habilidades pessoais (TEMPORÃO; PENELLO, 2010).

Nesse sentido, esta pesquisa justifica-se pela importância de verificar a prática dos profissionais de enfermagem relacionada ao aleitamento materno, no período gravídico e puerperal, especificamente, se é realizada visita domiciliar no puerpério imediato, com atividade de apoio e incentivo à amamentação. Teve como objetivo geral: compreender a influência da assistência de enfermagem, como suporte social, em relação ao aleitamento materno, no município de Cajazeiras (PB); e objetivos específicos: analisar como os enfermeiros promovem, incentivam e apoiam o aleitamento materno durante a assistência de enfermagem no período gravídico puerperal e identificar a ocorrência/enfoque da visita domiciliar realizada pelo enfermeiro à mulher no pós-parto imediato.

\section{Metodologia}

O presente estudo trata-se de uma pesquisa exploratória, com abordagem qualitativa, que foi realizada em uma unidade de saúde do município de Cajazeiras, na Paraíba. Participaram do estudo dezesseis mulheres que tiveram filhos no primeiro semestre de 2011 e realizaram consultas de pré-natal e de puerpério imediato na referida unidade. A idade das entrevistadas variou entre 18 a 37 anos; e as com idade entre 18 a 24 anos foram consideradas as mais jovens, pois algumas estavam na adolescência e outras na transição para a faze adulta, conforme o estabelecido pela Organização Mundial de Saúde (OMS) (adolescente - 10 a 19 anos) e pela Organização das Naçóes Unidas (ONU) (adultos jovens - 20 a 24 anos) (EISENSTEIN, 2004).

Seguindo os aspectos éticos para pesquisa envolvendo seres humanos, as mulheres concordaram em participar da pesquisa, mediante assinatura do Termo de Consentimento Livre e Esclarecido. Os sujeitos do estudo foram identificados em seus discursos através da codificação Entrevista 1 a Entrevista 16, na sequência das entrevistas, a fim de preservar o anonimato. Ressaltando que o projeto desta pesquisa foi aprovado pelo Comitê de Ética em Pesquisa, da Universidade Estadual da Paraíba (CAAE 0515.0.133.000-11).

A coleta de dados foi realizada no domicílio das pesquisadas, mediante entrevista, tendo como instrumento um roteiro estruturado, contendo questóes objetivas e subjetivas abordando os fatores relacionados à prática da amamentação. Dentre as questôes que nortearam a entrevista, destacam-se: durante o pré-natal, que atividade foi realizada pelo enfermeiro que incentivasse o aleitamento materno? Em qual momento da gestação ele the incentivou sobre aleitamento materno? Com quantos dias pós-parto o enfermeiro realizou visita domiciliar? Qual foi o enfoque dessa visita? Se você tivesse que eleger uma pessoa que foi ou ainda é muito importante para o sucesso da amamentação, qual seria? 
Os dados foram analisados por meio da forma temática tradicional, que trabalha com o recorte do texto em unidades de registro, que podem ser uma palavra, uma frase ou um tema, realizando a classificação e agregação dos dados (MINAYO, 2010). As temáticas emergentes (Incentivo ao aleitamento materno; Visita domiciliar no puerpério: realização e enfoque; $\mathrm{O}$ suporte social para a amamentação a partir das entrevistas) foram discutidas à luz da literatura pertinente.

\section{Resultados e Discussão}

\section{Caracterizando as pesquisadas}

Participaram desta pesquisa 16 mulheres. Quanto à idade, quatro mulheres tinham entre 25 e 37 anos; e doze, 18 a 24 anos. O tempo médio de aleitamento exclusivo entre elas foi de 150 dias e de 180 dias para aleitamento materno com complementaçáo. Tais achados são contrários ao estudo de Chaves et al. (2007), em que afirmam que mães nessa faixa etária amamentam por um tempo menor que mães mais adultas, uma vez que verificaram a mediana de aleitamento exclusivo de 90 dias e de aleitamento materno acompanhado de complemento, 120 dias.

Com relação ao grau de escolaridade, nove mulheres relataram de 6 a 11 anos de estudo e sete com 12 a 15 anos, revelando que, no geral, a escolaridade das pesquisadas era satisfatória para se alcançar uma melhor compreensão acerca dos benefícios da prática da amamentação. Como afirmam Coelho Junior e Borges-Andrade (2011), quanto maior o grau de instrução, maior a apreensão e desempenho da informação recebida.

Quanto à profissão, dez mulheres eram do lar, cinco tinham outras profissôes e uma era agricultora. $\mathrm{O}$ fato de o maior número de entrevistadas ser do lar é considerado positivo para a prática da amamentação exclusiva e, também, pode contribuir para um melhor cuidado com seus filhos, comparado com mães que trabalham fora do lar. Entretanto, não apontamos que o trabalho seja, necessariamente, incompatível com a prática do aleitamento materno, uma vez que existem alternativas como a ordenha manual e a licença maternidade, para possibilitar à mãe uma maior dedicação ao seu filho e propiciar a prática do aleitamento materno.

Com relação ao estado civil das mulheres, onze eram casadas e cinco solteiras. Tal fato é considerado positivo, pois a presença do companheiro pode favorecer a prática da amamentação, principalmente se ele incentivar, apoiar e ajudar nas tarefas em geral, tanto da casa, como nos cuidados com o filho.

A renda marcante entre as mulheres foi de 1 a 2 salários mínimos; e onze delas moravam com mais de três pessoas. Porém, apenas uma pessoa contribuía com a renda total da família. O fator renda e tempo de amamentação foram inversamente proporcionais, nesta investigação, pois percebemos que as famílias cujas mães amamentaram seus filhos por menos tempo apresentaram renda mais alta.

\section{Assistência de enfermagem na prática da amamentação}

Neste item buscamos, a partir das respostas das pesquisadas às questóes que nortearam as entrevistas, compreender a influência da assistência de enfermagem, como suporte social, em relação ao aleitamento materno. A partir dos textos resultantes das entrevistas, emergiram as seguintes temáticas: Incentivo ao aleitamento materno; Visita domiciliar no puerpério: realização e enfoque; $\mathrm{O}$ suporte social para a amamentação.

\section{Incentivo ao aleitamento materno}

No tocante à prática do enfermeiro com relação ao incentivo, apoio e promoção do aleitamento materno (AM), segundo os depoimentos das mulheres entrevistadas, somente 7 (sete) referiram ter recebido orientações no pré-natal, no momento mais indicado e conveniente, que corresponde especialmente ao $3^{\circ}$ trimestre de gestação, conforme ilustrado nas falas das entrevistadas 6 e 8 , a seguir:

Ela me orientou foi mais pro fim da gravidez. (Entrevista 6).

Quando a enfermeira veio me dizer alguma coisa, foi pra perto de ter. (Entrevista 8). 
O fato de nem todas as mulheres serem orientadas sobre o AM no pré-natal também foi observado no estudo de Demitto et al. (2010), realizado no município de Maringá, com uma população de 21 mulheres, das quais, apenas 6 (seis) foram orientadas por enfermeiros.

Tal evidência é preocupante, considerando que, para uma efetiva assistência de enfermagem à mulher durante o puerpério, de forma a promover sua adaptação às peculiaridades desse período, é primordial uma interação entre ela e o(a) cuidador(a); e que o processo de cuidar seja iniciado ainda durante a gestação e fortalecido no pós-parto (RODRIGUES et al., 2006).

Entre as 16 pesquisadas, 9 (nove) relataram não ter recebido orientações em nenhum momento da gestação sobre a importância do aleitamento materno, como ilustrado nas falas das entrevistadas 4 e 10, a seguir:

\section{A enfermeira não fez nada não, em nenhum momento mesmo. (Entrevista 4). \\ Na realidade, não teve nada de orientação não.}

(Entrevista 10).

Durante as entrevistas, algumas mulheres demonstraram insatisfação com a assistência de enfermagem, no tocante à orientação e apoio ao aleitamento materno.

Acerca do conhecimento sobre a temática, a maioria das mulheres que referiu ter algum conhecimento sobre o assunto informou que tinha sido adquirido através de vizinhos, familiares e agentes comunitários de saúde.

A prática do AM é apontada como prevenção de mais de 6 milhóes de mortes em crianças menores de 12 meses, a cada ano. Se a amamentação fosse praticada universalmente, mais de 2 milhóes de mortes poderiam ser evitadas. De acordo com Cruz et al. (2010), para que haja êxito na prática do aleitamento materno, as mães necessitam de apoio permanente durante a gravidez, nas consultas de pré-natal e após o parto, não só das suas famílias e amigos, como também e, principalmente, dos profissionais.

Lins et al. (2006) afirmam que o trabalho sobre orientação e incentivo ao aleitamento materno exclusivo deve ser iniciado no começo da gestaçáo, desde as primeiras consultas de pré-natal, dando mais ênfase ao assunto a partir do sétimo mês de gestação, uma vez que no inicio da gravidez a preocupação está focada nos exames, sexo da criança, na alimentaçáo da máe, entre outros.

Visita domiciliar no puerpério: realizaçáo e enfoque Uma das atividades inerentes à Estratégia Saúde da Família (ESF) é a visita domiciliar (VD), que proporciona ao profissional um maior contato com o espaço da família e, assim, identifica suas principais necessidades (DRULLA et al., 2009).

A esse respeito, é recomendado ao enfermeiro realizar a VD após o parto, de preferência imediatamente e nos primeiros dias, para que o aleitamento materno seja iniciado o mais precoce possível, auxiliando, assim, as mães nas primeiras mamadas do recém-nascido. O enfermeiro deve estar disponível, observando como está sendo a pega do recém-nascido, e respondendo a perguntas quanto ao aleitamento materno e demais intercorrências que surgirem (SILVA; KROST, 2009).

Nessa pesquisa, observamos, pelos relatos das mulheres, que a visita domiciliar realizada por enfermeiros não foi satisfatória, uma vez que apenas duas mulheres relataram ter recebido essa visita, conforme relatos das entrevistadas 1 e 13, a seguir. Fato preocupante, pois a VD nesse momento é de fundamental importância para a promoção à saúde da criança e incentivo à prática do AM.

\section{(...), ganhei num dia, com dois dias fui pra casa, ai no outro ela veio aqui em casa, no $4^{\circ}$ dia. (Entrevista 1). \\ Com uns 15 dias ela veio aqui. (Entrevista 13).}

No campo da atençáo profissional da enfermagem, em particular, sublinha-se a importância do acompanhamento puerperal, especialmente no que se refere ao apoio necessário à mulher e atenção às suas necessidades (SOUZA et al., 2008). Contrariamente, encontramos oito mulheres que não receberam visitas após o parto, o que está ilustrado nos relatos a seguir: 
A mim mesmo não, nenhum dia, ninguém veio aqui não. (Entrevista 6).

Não, ela não chegou a fazer visita a mim nenhuma vez (...). (Entrevista 5).

Como expresso nos discursos das Entrevistas 5 e 6, a VD não existiu para essas mulheres, pelo menos sendo realizada pela equipe de enfermagem. Salientando que essas mulheres enfrentaram dificuldades com a amamentação e não amamentaram 120 dias completos. Tal evidência talvez pudesse ter sido evitada se tivesse havido o acompanhamento do profissional de enfermagem, incentivando e ajudando em suas principais dificuldades, fato que náo aconteceu, e logo vieram a desmamar. Este achado coaduna a afirmativa de Parizotto e Zorzi (2008), de que um dos fatores de risco que se destaca para o desmame é exatamente poucas visitas domiciliares ou nenhuma.

Observamos, também, que a maioria das visitas, quando aconteceu após o parto, foi realizada por Agentes Comunitários de Saúde (ACS), conferindo um total de seis entrevistadas, como ilustrado nos depoimentos a seguir:

A enfermeira nunca veio não, quem veio com uns 5 dias foi a ACS. (Entrevista 16).

A ACS quem fez, mais ou menos na segunda semana que voltei do hospital. (Entrevista 2).

Tal achado merece destaque, pois a visita domiciliar dos agentes comunitários de saúde, no último mês de gestação e na primeira semana de vida da criança, é uma ação prioritária de vigilância à saúde da mãe e do bebê, e é de fundamental importância para o incentivo, orientação e apoio à amamentação (BRASIL, 2004).

Ao questionar às mulheres acerca do enfoque dado pelos ACS durante as visitas, observamos que algumas ficaram satisfeitas com a assistência prestada pelo ACS, uma vez que responderam suas dúvidas, ensinaram mais sobre a prática de amamentar, entre outros, conforme relatos a seguir:

Foi pra saber se tava amamentando, se a criança tava bem. Ensinou também como botava o menino pra mamar. (Entrevista 9).
Esta satisfação evidenciada na entrevista 9 confirma a importância do trabalho do ACS, pois ele sempre mantém contato direto com as mães e pode ainda orientar sobre os benefícios do leite materno. Entretanto, estudos comprovam que esses profissionais nem sempre têm sustentação científica para abordar questôes mais complexas e, às vezes, não podem oferecer o suporte adequado às mães com alguma dificuldade em amamentar. Por isso, é necessária uma capacitação para um embasamento mais científico desses profissionais (VASCONCELOS, 2009).

\section{O suporte social para a amamentaçáo}

A amamentação é uma arte a ser apoiada, aprendida e ensinada, não só pelos profissionais de saúde, mas pela sociedade como um todo, destacando-se o papel da família. Como afirmam Teixeira et al. (2011), cada pessoa na família tem características próprias, mas, para se manter a harmonia no processo de aleitamento materno, faz-se necessário uma troca de experiências, vivências e conhecimentos, uma harmonia de relação familiar, cujo objetivo é o sucesso do aleitamento materno.

$\mathrm{Na}$ prática, temos percebido que a nutriz sempre elege um membro familiar, geralmente um mais velho, mais experiente e, particularmente, que já tenha vivenciado a maternidade, o que gera confiança, apoio e troca de informações necessárias. Nesse sentido, Barreira e Machado (2004) apontaram a avó materna como a pessoa escolhida, o que se assemelhou ao nosso estudo, em que foram identificadas 8 (oito) mulheres com o mesmo relato, como ilustramos a seguir:

Se não fosse minha mãe eu não teria nem começado a amamentar. (Entrevista 1).

Minha máe foi quem fez tudo pra eu dar de mamar, me incentivava muito, dizia que era bom pra mim e pro meu filho. (Entrevista 12).

$\mathrm{O}$ apoio e o incentivo à amamentação podem vir $50 \%$ de suas mães e $20 \%$ de sogras. Os demais $30 \%$ restantes envolvem irmãs, cunhadas, primas e maridos, demonstrando que as avós representam a maior força dentre os familiares no processo de amamentação (BARREIRA; MACHADO, 2004). 
Contrariamente, Susin et al. (2005), em pesquisa com 601 mães de Porto Alegre, encontraram que a ausência de contato diariamente com a avó materna foi um fator que contribuiu para a manutenção da amamentação por um período de seis meses. As autoras afirmaram que as avós podiam influenciar negativamente na amamentação, tanto na duraçáo, quanto na exclusividade.

Zanin e Schacker (2010) afirmam que as mães das nutrizes percebem a prática do aleitamento materno como uma herança transmitida de uma geração para outra; de mãe para filha, que é identificada a partir dos comportamentos repetitivos. Assim sendo, a influência da avó pode provocar repercussóes positivas ou não no processo de amamentação de seus netos.

É evidenciado que o saber dos mais velhos, daqueles em quem a família confia sua herança cultural, tem papel de respeito e gratidão. Tal saber é valorizado e inserido nas açóes de cuidado em continuação à história familiar. Deste modo, sua influência ou não para o aleitamento materno tem valor na organização da estrutura familiar, perpetuando ou não esta prática de cuidados à saúde (TEXEIRA et al., 2011).

No nosso estudo destacou-se também a influência do companheiro para 4 (quatro) mulheres, acerca do apoio na prática da amamentação, como visto a seguir:

Todos me ajudaram, mas meu marido me ajudava muito mesmo. (Entrevista 2).

Se não fosse o pai do meu filho, me ajudando toda noite, talvez eu náo tivesse conseguido.

(Entrevista 5).

Nos depoimentos das mulheres 2 e 5, observamos que os companheiros foram muito participativos no apoio ao aleitamento materno exclusivo. $\mathrm{O}$ aleitamento materno, na maioria das culturas, tem sido considerado pela sociedade responsabilidade exclusivamente da mulher. Entretanto, no nosso estudo foram encontrados depoimentos onde as mulheres relataram sobre a importância do apoio do marido/ pai no incentivo à prática da amamentação. Carvalho (2003) afirma que o pai deve ter um papel importante na divisão de responsabilidade, desde os primeiros dias de nascimento da criança.

Segundo Costa (2007), essa nova concepção da participação mais efetiva dos homens no cotidiano familiar, particularmente no cuidado para com a criança, vem sendo comumente veiculada como a "nova paternidade". A esse respeito, Jardim e Costa (2009) afirmam que essa nova paternidade inclui não apenas o suporte econômico de sustentação da família, mas também a expressão de sentimentos e a participação em todos os aspectos do cotidiano familiar, incluindo os cuidados com o bebê e o seu desenvolvimento.

No entanto, é necessário enfatizar que, além do apoio familiar influenciar na prática da amamentação, os profissionais de saúde também se destacam no vínculo afetivo estabelecido desde as primeiras consultas de pré-natal até as consultas puerperais, como principal aproximação e abertura para a confiança depositada nos mesmos e, assim, contribuírem para o sucesso da prática da amamentação.

Com relação à ajuda da enfermeira, apenas duas mulheres se pronunciaram, o que está ilustrado nos depoimentos a seguir:

Quem me ajudou muito foi a enfermeira. (Entrevista 15).

Pra mim, quem me ajudou muito foi a enfermeira do banco de leite. (Entrevista 16).

Embora tenha havido satisfação entre as mulheres 15 e 16, observamos que a maioria das entrevistadas não recebeu orientaçôes, nem tampouco a visita domiciliar da enfermeira. Nesse sentido, Marasquin et al. (2004) afirmam que ainda há muito para ser feito em relação à assistência de enfermagem direcionada à prática do aleitamento materno.

Desse modo, justifica-se a necessidade de o profissional se colocar disponível em compartilhar as inúmeras situações que envolvem a experiência da mulher em amamentar, e compreendê-la em todas as dimensóes do ser mulher (LEITE et al., 2004). Amamentar engloba crenças, tabus, experiências que muitas vezes contribuem de forma negativa para efetivação da amamentação; surge aí a necessidade do profissional atuar 
ajudando a enfrentar essas situaçóes, transmitindo confiança e segurança.

Para tanto, ao enfermeiro cabe procurar capacitar-se em aleitamento materno para atuar junto à população, náo somente prestando assistência, mas na promoção e educação continuada. De acordo com o nosso estudo, podemos perceber que ainda falta muito para atingir essa qualificação. Ao serem questionadas se tinham alguma sugestáo para o desenvolvimento da assistência ofertada a elas, algumas mulheres relataram que poderia ser melhorada, conforme ilustrado nas falas das entrevistadas 3 e 6 , a seguir:

Era bom que explicasse mais, porque foi muito pouco. (Entrevista 6).

Então, a enfermeira deveria ter vindo visitar, observar mais. (Entrevista 3).

A importância do profissional de enfermagem é indiscutível, pois ele tem certa autonomia para desenvolver uma melhor assistência voltada às gestantes e puérperas, não apenas para diminuir os altos índices de desmame, mas, sobretudo, tornar este ato uma experiência saudável e prazerosa. Durante as entrevistas, pudemos apreender certo descontentamento em relaçấo à assistência direcionada a elas, pois, com relação ao aleitamento materno exclusivo, ocorreram casos de desmame precoce por razóes facilmente controláveis.

Os resultados obtidos mostraram que o tempo de amamentação está bem abaixo do recomendado pelo Ministério da Saúde, sendo comprovada a necessidade de maior conscientizaçáo dos profissionais em preparar as máes durante o pré-natal e priorizar a assistência no puerpério imediato, realizando visita domiciliar, aconselhamento, acolhimento. Enfim, prestar assistência qualificada à mãe no puerpério imediato, considerando esta ser uma medida de extrema importância para o aumento dos índices de aleitamento materno infantil (ADAMS; RODRIGUES, 2010).

\section{Conclusões}

O aleitamento materno é considerado a nutrição ideal para todos os bebês, sendo indiscutível sua importância para a saúde da criança, uma vez que oferece proteção imunológica.

A partir dessa pesquisa, nos foi possível compreender a influência da assistência de enfermagem na prática da amamentação no puerpério imediato; identificamos como se deu a frequência de visitas realizadas pelos profissionais da saúde da Estratégia Saúde da Família às puérperas e qual foi o enfoque dessa visita, quando aconteceu.

No tocante ao incentivo à prática da amamentação exclusiva por parte dos profissionais de enfermagem, percebemos que essa contribuição não foi satisfatória, uma vez que as mulheres participantes relataram que passaram por dificuldades, às vezes de fácil solução, mas como não houve apoio e incentivo, acabaram abandonando a amamentação.

Partindo do princípio que o puerpério imediato é decisivo para o sucesso da amamentação, pois é quando as mães enfrentam as maiores dificuldades com o aleitamento materno, a adaptação da mãe ao recém-nascido e viceversa, os cuidados em geral, etc., esta pesquisa evidenciou que nesta fase houve certo distanciamento do enfermeiro como suporte social capacitado.

Assim, é importante que o profissional de enfermagem realize mais visitas domiciliares, não apenas focadas em aspectos do exame físico, a exemplo de verificar pressão arterial, mas que, próximo à população, crie vínculo profissional/afetivo qualificado, gerador de confiança, para que a população sinta-se à vontade e então partilhe suas dificuldades, angústias, medos e que estes possam ser superados. Enfim, que a visita domiciliar seja um instrumento cotidiano para açóes de promoção da saúde, na qual o profissional esteja atento às especificidades e particularidades de cada família.

Ademais, faz-se necessária a implantação de ações de educação e incentivo ao aleitamento materno na Unidade Básica de Saúde, possibilitando maiores oportunidades de divulgar e promover o aleitamento materno, incentivando as mães a amamentarem seus filhos. Desta forma, poder contribuir para a diminuição do índice de desmame precoce.

Frente ao exposto, esta pesquisa evidencia que a assistência de enfermagem prestada às mães que estão no processo de aleitamento materno ainda é insuficiente para garantir uma prática adequada de amamentação, como preconiza o Ministério da Saúde. 


\section{Referências}

ADAMS, F.; RODRIGUES, F. C. P. Promoção e apoio ao aleitamento materno: um desafio para Enfermagem. Vivências: Revista Eletrônica de Extensão da URI, Erechim, v. 6, n. 9, p. 162-166, maio 2010. Disponível em: <http://www.reitoria.uri.br/ vivencias/ Numero_009/artigos/artigos_vivencias_09/n9_16.pdf> Acesso em: 19 nov. 2012.

AMORIM, M. M.; ANDRADE, E. R. Atuação do enfermeiro no PSF sobre aleitamento materno. Revista Científica Perspectivas online, Campos dos Goytacazes, v. 3, n. 9, p. 93-110, 2009. Disponível em: <http://www.perspectivasonline.com.br/revista/2009vol3n9/ volume\%203(9)\%20artigo9.pdf>. Acesso em: 10 jul. 2012.

BARREIRA, S. M. C.; MACHADO, M. F. A. S. Amamentação: compreendendo a influência do familiar. Acta Scientiarum. Health Sciences, Maringá, v. 26, n. 1, p. 11-20, 2004. Disponível em: <http:// eduemojs.uem.br/ojs/index.php/ActaSciHealthSci/article/view /1606/1052>. Acesso em: 18 nov. 2012.

BRASIL. Ministério da Saúde. Agenda de compromissos para a saúde integral da criança e redução da mortalidade infantil. Brasília: MS, 2004. Disponível em: <http://bvsms.saude .gov.br/bvs/publicacoes/ agenda_compro_crianca.pdf>. Acesso em: 21 nov. 2012.

CARVALHO, M. L. M. Participação dos pais no nascimento em maternidade pública: dificuldades institucionais e motivação dos casais. Cadernos de Saúde Pública, Rio de Janeiro, v. 19, n. 2, p. 389398, 2003. Disponível em: <http://www.scielo.br/pdf/csp/ v19s2/ a20v19s2.pdf>. Acesso em: 22 nov. 2012.

CHAVES, R. et al. Fatores associados com a duração do aleitamento materno. Jornal de Pediatria, Rio de Janeiro, v. 83, n. 3, p. 241-246, 2007. Disponível em <http://www.scielo.br/scielo.php?script=sci_ arttext\&pid=S0021-75572007000400009>. Acesso em: 21 nov. 2012.

COELHO JUNIOR, F. A.; BORGES-ANDRADE, J. E. Efeitos de variáveis individuais e contextuais sobre desempenho individual no trabalho. Estudos de Psicologia, Natal, v. 16, n. 2, p. 111-120, maio/ago. 2011. Disponível em: <http://www.scielo.br/pdf/epsic/v16n2/ v16n2a01. pdf>. Acesso em: 01 mar. 2011.

COSTA, C. R. Representação do papel do pai no aleitamento materno. 2007. 132f. Dissertação (Mestrado em Nutrição Clínica) - Faculdade de Ciências da Nutrição e Alimentação, Universidade do Porto, Porto, 2007.

CRUZ, S. H. et al. Orientações sobre amamentação: a vantagem do Programa de Saúde da Família em municípios gaúchos com mais de 100.000 habitantes no âmbito do PROESF. Revista Brasileira de Epidemiologia, São Paulo, v. 13, n. 2, p. 259-267, 2010. Disponível em: <http://www.scielo.br/pdf/rbepid/v13n2/08.pdf>. Acesso em: 21 nov. 2012.
DEMITTO, M. O. et al. Orientações sobre amamentação na assistência pré-natal: uma revisão integrativa. Revista da Rede de Enfermagem do Nordeste, Fortaleza, v. 11, n. esp., p. 223-229, 2010. Disponível em: <http://www.revistarene.ufc.br/edicaoespecial/ a25v11 esp_n4.pdf>. Acesso em: 20 nov. 2012.

DRULLA, A. G. et al. A visita domiciliar como ferramenta ao cuidado familiar. Cogitare Enfermagem, Curitiba, v. 14, n. 2, p. 667-674, out. / dez. 2009. Disponível em: <http://ojs.c3sl. ufpr.br/ojs2/index.php/ cogitare/article/view/16380/10861>. Acesso em: 17 nov. 2012.

EISENSTEIN, E. Adolescência: definições, conceitos e critérios. Adolescência \& Saúde, Rio de Janeiro, v. 2, n. 2, p. 6-7, abr./jun. 2005. Disponível em: <http://www.adolescenciaesaude. com/detalhe_ artigo.asp?id=167>. Acesso em: 01 mar. 2013.

JARDIM, A. M. S.; COSTA, N. R. A. O reflexo da nova paternidade em um posto de saúde. Revista Investigação em Ensino de Ciências, Porto Alegre, v. 9, n. 1, p. 7-16, jan./abr. 2009. Disponível em: $<$ http://publicacoes.unifran.br/index.php/investigacao/article/ view/33/5>. Acesso em: 01 mar. 2013.

LEITE, A. et al. Comunicação não verbal: uma contribuição para o aconselhamento em amamentação. Revista Latino-americana de Enfermagem, São Paulo, v. 12, n. 2, p. 258-264, 2004. Disponível em: <http://www.scielo.br/scielo.php?script=sci_arttext\&pid =S0104-11692004000200016>. Acesso em: 20 nov. 2012.

LINS, G. F. A. C. et al. Amamentação e tipo de parto: uma avaliação envolvendo as gestantes do estudo multicêntrico sobre saúde reprodutiva no Brasil realizado em Natal-RN, 2000. Revista Publ/Ca, Natal, a. II, p. 29-37, 2006. Disponível em: <http:// www.reitoria. ufrn.br/ ojs/index.php/publica/article/viewArticle/24>. Acesso em: 15 nov. 2012.

MARASQUIN, H. G. et al. Visita domiciliar: o olhar da comunidade da quadra 603 Norte. Revista da UFG, Palmas, v. 6, n. especial, dez. 2004. Disponível em: <http://www.proec.ufg. br/revista_ufg/ familia/H_visita.html>. Acesso em: 20 nov. 2012.

MARINHO, C.; LEAL, I. P. Os profissionais de saúde e o aleitamento materno: um estudo exploratório sobre as atitudes de médicos e enfermeiros. Psicologia, saúde \& doenças, Lisboa, v. 5, n. 1, p. 93105, jul. 2004. Disponível em: <http://www.scielo.oces.mctes. pt/ pdf/psd/v5n1/v5n1a07.pdf>. Acesso em: 20 jun. 2012.

MINAYO, M. C. O desafio do conhecimento: pesquisa qualitativa em saúde. 12. ed. São Paulo: Hucitec, 2010.

PARIZOTTO, J.; ZORZI, N. T. Aleitamento Materno: fatores que levam ao desmame precoce no município de Passo Fundo, RS. O Mundo da Saúde, São Paulo, v. 32, n. 4, p. 466-474, 2008. Disponível em: <http://www. saocamilosp.br/pdf/mundo_saude/65/08_ Aleitamento_baixa.pdf>. Acesso em: 19 nov. 2012. 
RODRIGUES, D. P. et al. O domicílio como espaço educativo para o autocuidado de puérperas: binômio mãe-filho. Texto \& Contexto - Enfermagem, Florianópolis, v.15, n.2, p. 277-286, abr./jun. 2006. Disponível em: < http://redalyc.uaemex.mx/pdf/714/71415212. pdf>. Acesso em: 20 nov. 2012.

SILVA, A.; KROST, O. Comentários sobre a licença-maternidade e as inovações da lei no 11.770/08. Revista Eletrônica Curso de Direito Unifacs, Salvador, v. 106, p. 1-10, 2009. Disponível em: < http:// www.revistas.unifacs.br/index.php/redu/article/view/635>. Acesso em: 19 nov. 2012.

SOUZA, K. V. et al. A consulta puerperal: demandas de mulheres na perspectiva das necessidades sociais em saúde. Revista Gaúcha de Enfermagem, Porto Alegre, v. 29, n. 2, p. 175-181, jun. 2008. Disponível em: <http://seer.ufrgs.br/ RevistaGauchadeEnfermagem/ article/view/5532/3149>. Acesso em: 21 nov. 2012.

SUSIN, L. R. O. et al. Influências das avós na prática do aleitamento materno. Revista de Saúde Pública, São Paulo, v. 39, n. 2, p. 141147, 2005. Disponível em: <http://www.scielosp. org/pdf/rsp/ v39n2/24034.pdf>. Acesso em: 21 nov. 2012.

SYDRONIO, K. A enfermagem brasileira tecendo as redes do conhecimento no assistir em amamentação. 2006. 227f. Tese (Doutorado em Saúde da Criança e da Mulher) - Instituto Fernandes Figueira, FIOCRUZ, Rio de Janeiro, 2006.
TEIXEIRA, M. A. et al. A prática da amamentação no cotidiano familiar - um contexto intergeracional: influência das mulheresavós. Revista Temática Kairós Gerontologia, São Paulo, v. 14, n. 3, p. 205-221, jun. 2011. Disponível em: <http://www.revistas.pucsp. br/index.php/kairos/article/view/6501/4713> Acesso em: 20 nov. 2012

TEMPORÃO, J. G.; PENELLO, L. M. Determinação social da saúde e ambiente emocional facilitador: conceitos e proposição estratégica para uma política pública voltada para a primeira infância. Saúde em Debate, Rio de Janeiro, v. 34, n. 85, p. 187-200, abr./jun. 2010. Disponível em: < www.universidadesaudavel.com. br/wp-content/.../download.php?id...>. Acesso em: 20 nov. 2012.

VASCONCELOS, S. A. Capacitação dos agentes comunitários de saúde para melhoria da adesão ao aleitamento materno exclusivo no PSF Boqueirão do Cesário do município Beberibe - CE. 2009. $27 f$. Monografia (Especialização em Práticas Clínicas em Saúde da Família) - Escola de Saúde Pública do Ceará, Fortaleza, 2009.

ZANIN, L. C.; SCHACKER, L. C. Avós maternas: incentivadoras da amamentação? Revista Conhecimento Online, Novo Hamburgo, v. 1, n. 2, p. 1-13, mar. 2010. Disponível em: <http://www.feevale.br/ site/files/documentos/pdf/35211.pdf>. Acesso em: 10 nov. 2012.

Recebido para publicação em Julho/2012

Versão final em: Março/2013

Conflito de interesse: Não houve.

Suporte financeiro: Inexistente. 